\title{
Synthesis and Characterization of Copper Complex of Salicylaldehyde Benzoyl Hydrazone
}

\author{
Sabita Shrestha ${ }^{*}$ and Sudha Maharjan \\ Central Department of Chemistry, Tribhuvan University, Kirtipur, Kathmandu, Nepal. \\ E-mail: shresthasabita@hotmail.com
}

\begin{abstract}
Copper complex of type $\left[\mathrm{Cu}(\mathrm{SBH})_{2}\right]$ was synthesized and characterized by different analytical procedure and spectral studies. The complex was insoluble in common organic solvents and it has melting point in between $254-258^{\circ} \mathrm{C}$. Infrared spectrum showed the bonding through enolic oxygen and azomethine nitrogen. The electronic spectral studies showed that the $\mathrm{Cu}(\mathrm{II})$ is in tetrahedral coordination environment.
\end{abstract}

Keywords: Salicylaldehyde Benzoyl Hydrazone, Copper Complex

\section{Introduction}

Coordination properties of Schiff Base towards metal ions have extensively investigated due to their biological activity and variable bonding potentialities in forming complexes. Schiff base containing the $-\mathrm{RC}=\mathrm{N}$ - group have gained importance because of physiological and pharmacological activities associated with them. They constitute an interesting class of chelating agents capable of co-coordinating with one or more metal ions giving mononuclear as well as polynuclear metal complexes ${ }^{1}$.

Salicylaldimines, $\mathrm{C}_{6} \mathrm{H}_{4} \mathrm{OHCH}=\mathrm{NR}$, and other ligands essentially containing a $\mathrm{C}=\mathrm{N}$ group have been popularly called Schiff bases, which are versatile multidentate ligands capable of bonding from several alternate sites resulting in the formation of metal complexes having suitable properties for theoretical studies and practical applications ${ }^{1}$. In this paper we present the Copper complex of salicylaldehyde benzoyl hydrazone, $\mathrm{C}_{6} \mathrm{H}_{4} \mathrm{OHCH}=\mathrm{NNHCOC} \mathrm{C}_{6} \mathrm{H}_{5}$, and characterized the complex by analytic procedure (such as metal, ligand, water, anion estimation) and spectral studies (IR and electronic spectra). The hydrazone can coordinate to transition metals either in the enolic form[1] or in ketonic form [2] as shown in Fig. 1.

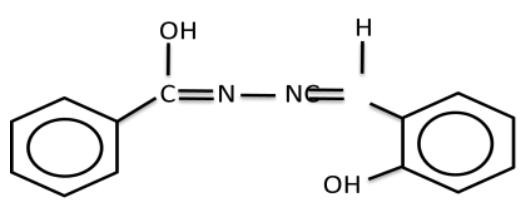

[1]

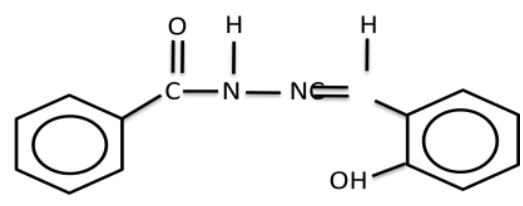

[2]

Figure 1: Enolic [1] and Ketonic [2] forms of Salicylaldehyde benzoyl hydrazone

\section{*Corresponding author}




\section{Experimental Methods}

\section{Starting Materials}

Transition metal salt $\left(\mathrm{MX}_{2} \cdot \mathrm{nH}_{2} \mathrm{O}\right.$, where $\left.\mathrm{M}=\mathrm{Cu}^{2+}\right)$ was obtained from SD fine chemical Ltd (Mumbai, India). Methyl benzoate, Salicylaldehyde were of CDH Laboratory Reagent, New Delhi. The solvents ethanol and benzene were purchased from Qualigens Chemical Company and used without further purification.

\section{Synthesis of the Ligand}

The ligand, Salicylaldehyde Benzoyl Hydrazone (SBH) was synthesized in two steps.

\section{Synthesis of Benzoic Acid Hydrazide(BH)}

The benzoic acid hydrazide, $\mathrm{C}_{6} \mathrm{H}_{5} \mathrm{CONHNH}_{2}$, $\mathrm{BH}$, was prepared by following literature procedure ${ }^{2}$ by refluxing together ethanolic solutions of ethyl benzoate $(30 \mathrm{ml})$ and hydrazine hydrate $(10 \mathrm{ml})$ in $1: 1$ mole ratio for about six to eight hours and leaving the solution overnight (Scheme 1). The products were filtered and thoroughly washed with distilled water. Thus obtained hydrazide was recrystallized from hot benzene.

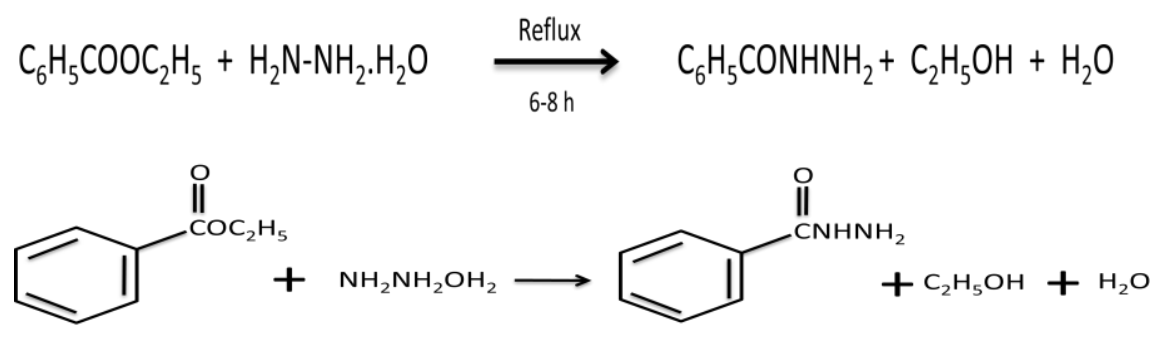

Scheme 1: Synthesis of Benzoic Acid Hydrazide

The yield was found to be $60 \%$ and the m. p. was $110{ }^{\circ} \mathrm{C}\left(\mathrm{Lit}^{2} .111^{\circ} \mathrm{C}\right)$.

The benzoic acid hydrazide is insoluble in benzene but soluble in ethanol, methanol, conc. $\mathrm{H}_{2} \mathrm{SO}_{4}$, $\mathrm{HNO}_{3}$ and polar solvents such as DMF and DMSO.

\section{Synthesis of Salicylaldehyde Benzoyl Hydrazone(SBH)}

Hydrazide Schiff Base or hydrazone is prepared by condensation of hydrazide with a compound containing active carbonyl group, i. e. aldehyde or ketone. Aldehydes, in general, yield $\mathrm{N}$-amidoaldimines while ketones yield $\mathrm{N}$-amido ketimines ${ }^{3}$. In this work, salicylaldehyde benzoyl hydrazone, a hydrazide Schiff base is prepared by condensation of benzoic acid hydrazide (5.44 $\mathrm{g}$ dissolved in ethanol) with salicylaldehyde ( $4.88 \mathrm{~g}$ or $4.1 \mathrm{ml}$; wt. per $\mathrm{ml}=1.164-1.167 \mathrm{~g}$ ) (Scheme 2$)$ in 1:1 mole ratio. After mixing these two solutions it was heated for few minutes which was left overnight. The pale yellow crystalline solid formed was then filtered and washed 2-3 times with ethanol and left to dry. The yield was found to be $78 \%$ and the m. p. was found to be $177^{\circ} \mathrm{C}\left(\mathrm{Lit}^{1} .180^{\circ} \mathrm{C}\right)$.

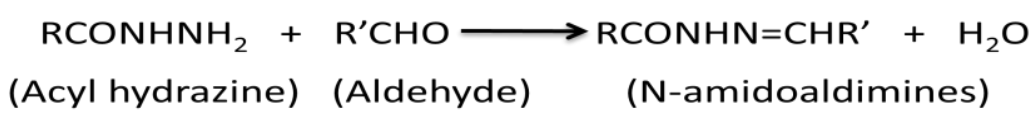

Where, $\mathrm{R}=-\mathrm{C}_{6} \mathrm{H}_{5}$ and $\mathrm{R}^{\prime}=-\mathrm{C}_{6} \mathrm{H}_{4}(\mathrm{OH})$ 


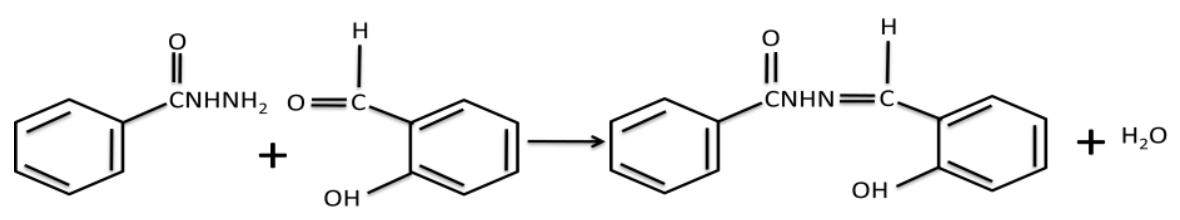

Scheme 2: Synthesis of Salicylaldehyde Benzoyl Hydrazone

The ligand, Salicylaldehyde Benzoyl Hydrazone, is sparingly soluble in benzene, ether and acetone but soluble in ethanol only when hot but highly soluble in DMF and DMSO.

\section{Characterization of the Ligand}

The structure of the prepared ligand (Fig. 2) was established on the basis of melting point and infrared data.

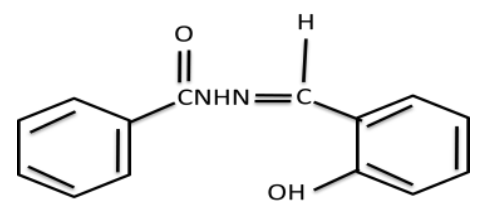

Figure 2: Salicylaldehyde Benzoyl Hydrazone

\section{Synthesis of the Complex}

Ethanolic solutions of $\mathrm{SBH}(5 \mathrm{mmol} / 1.2 \mathrm{~g}$ in $50 \mathrm{ml})$, and $\mathrm{CuCl}_{2} 2 \mathrm{H}_{2} \mathrm{O}(5 \mathrm{mmol} / 0.85 \mathrm{~g}$ in $10 \mathrm{ml})$ were mixed together and was heated for few minutes on the water bath which resulted in the formation of brown precipitate. It was then left overnight. The precipitate formed was then filtered, washed with ethanol and dried over fused $\mathrm{CaCl}_{2}$.

\section{Characterization of the Complex}

After establishing the chemical composition, the complex was studied by physical and chemical techniques for elucidating their coordination number, bonding sites and stereochemistry. The chemical and physical methods employed for structural investigation of the complexes in the present work are: (i) metal estimation (ii) ligand estimation (iii) dehydration stud (iv) anion estimation (v) electronic spectroscopy and (vi) infrared spectroscopy.

\section{Analytical Procedures}

Metal content of the complex was estimated iodometrically ${ }^{4}$. For this about $0.1 \mathrm{~g}$ of complex was accurately weighed and digested with aqua regia followed by conc. $\mathrm{H}_{2} \mathrm{SO}_{4}$. The white residue was then extracted with few drops of dil. $\mathrm{HCl}$ and distilled water into a conical flask to which $10 \mathrm{ml}$ of $10 \% \mathrm{KI}$ solution was added. It was finally diluted to about $75 \mathrm{ml}$. The flask was then covered with watch glass and allowed to stand in dark for few minutes. The liberated iodine was titrated against standard sodium thiosulphate solution using starch as indicator. The amount of copper was calculated by using relation:

$$
1 \mathrm{ml} \text { of } 1 \mathrm{~N} \mathrm{Na}_{2} \mathrm{~S}_{2} \mathrm{O}_{3} \equiv 0.06354 \text { gm of Copper }
$$


The ligand content of the complex was estimated by calibration curve method ${ }^{1}$. In this method, a weighed quantity of the complex was dissolved in $10 \mathrm{ml}$ of $6 \mathrm{~N} \mathrm{HCl}$ and titrated against a standard solution $(0.1 \mathrm{~N})$ of $\mathrm{KBrO}_{3}$ using methyl orange as indicator. The ligand content was adjudged from a calibration curve which was constructed by plotting the data of at least five sets of titrations where, in each case, a varying amount of the ligand was dissolved in $10 \mathrm{ml}$ of $6 \mathrm{~N} \mathrm{HCl}$ and the solution was titrated against a standard solution of $\mathrm{KBrO}_{3}$.

The chloride content in the complex was determined gravimetrically as Silver Chloride ${ }^{4}$. Dehydration studies of the complexes were done by heating the samples in two stages $\left(110^{\circ} \mathrm{C}\right.$ and $\left.150^{\circ} \mathrm{C}\right)$ for one hour and recording the loss of weight at each stage. The data were used for calculating the amounts of lattice water and coordinated water.

\section{Physico-Chemical Measurements}

Infrared Spectra of the ligand salicylaldehyde benzoyl hydrazone and its copper complex were obtained on $\mathrm{KBr}$ pellets on ABB, FTLA2000-104 in $4000-400 \mathrm{~cm}^{-1}$ range. Electronic absorption spectra of the copper and cobalt complexes were obtained on 6715 UVVIF spectrophotometer (Jenway) in solution state in $400-800 \mathrm{~nm}$ wavelength range.

\section{Results and Discussion}

\section{General Behaviors}

The ligand, salicylaldehyde benzoyl hydrazone in this study form 1:2 (M: L) complexes. The reaction between the ligand and metal salt is represented by following equation:

$$
\mathrm{CuCl}_{2} 2 \mathrm{H}_{2} \mathrm{O}+2(\mathrm{SBH}) \rightarrow\left[\mathrm{Cu}(\mathrm{SBH})_{2}\right]+2 \mathrm{HCl}+2 \mathrm{H}_{2} \mathrm{O}
$$

The complex is intensely colored and stable powder, which melt around $254-258{ }^{\circ} \mathrm{C}$. The yield of the complex is found to be $70 \%$ (Table 1). The complex is insoluble in water, ethanol, benzene and soluble in dimethyl sulphoxide and dimethyl formamide. The complex corresponds to formula $\left[\mathrm{Cu}(\mathrm{SBH})_{2}\right]$. It doesn't contain any anions.

Table 1: Analytical Data of Copper Complex of SBH.

\begin{tabular}{|l|l|l|l|l|}
\hline $\begin{array}{l}\text { Complex, } \\
\text { Color } \\
\text { Yield }(\%)\end{array}$ & $\begin{array}{l}\text { Empirical } \\
\text { Formula } \\
(\text { FormulaWt. })\end{array}$ & $\begin{array}{l}\text { M. P. } \\
\left({ }^{\circ} \mathrm{C}\right)\end{array}$ & Metal (\%) & $\begin{array}{l}\text { Ligand } \\
(\%)\end{array}$ \\
\hline $\begin{array}{l}{\left[\mathrm{Cu}(\mathrm{SBH})_{2}\right]} \\
\text { Brown, }(70 \%)\end{array}$ & $\begin{array}{l}\mathrm{CuC}_{28} \mathrm{H}_{22} \mathrm{O}_{4} \mathrm{~N}_{4} \\
(541)\end{array}$ & $254-258$ & $\begin{array}{l}12.25 \\
(11.64)\end{array}$ & $\begin{array}{l}85.15 \\
(87.61)\end{array}$ \\
\hline
\end{tabular}

( ) calculated value

\section{Dehydration Studies}

Water in inorganic salts may be classified as lattice or coordinated water. The lattice water denotes water molecules trapped in the crystalline lattice by weak H-bonds to the anion or by weak ionic bonds to the metal or by both, where as the coordinated water means water molecule bonded to the metal through a partially covalent bond.

The dehydration studies of complex showed no weight loss occurs at temperature $110{ }^{\circ} \mathrm{C}$ and $150{ }^{\circ} \mathrm{C}$ i. e. the complex does not contain any lattice and coordinated water molecules. 


\section{Infrared Spectra}

Infrared spectroscopy is one of the most common spectroscopic techniques used for structural elucidation of metal complexes and compound identification. The assignments of IR spectral bands most useful in establishing the structural identity of the ligand and its complexes are listed in Table 2 and shown in Fig. 3 and 4.
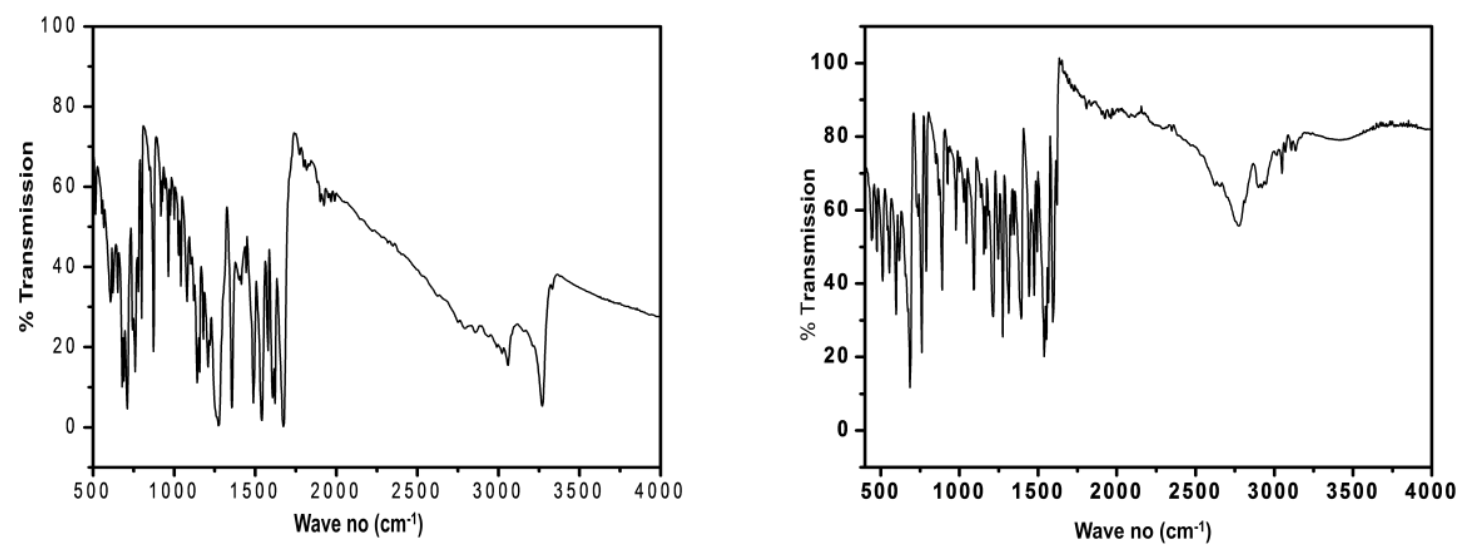

Figure 3 (left): Infrared Spectrum of Salicylaldehyde Benzoyl Hydrazone. Figure 4 (right): Infrared Spectrum of Copper Complex Benzoyl Hydrazone of Salicylaldehyde

Infrared spectra of the ligand, SBH, has several prominent bands at 3280, and $1630 \mathrm{~cm}^{-1}$ due to $v(\mathrm{~N}-$ $\mathrm{H})+v(\mathrm{OH})$ and $v(\mathrm{C}=\mathrm{N})$ stretching modes respectively. The amide (I, II, III) bands characteristic of $>\mathrm{CONH}$ - group are observed at 1675,1535 and $1275 \mathrm{~cm}^{-1}$ respectively indicating that the ligand exist in the keto form in the solid state ${ }^{5}$.

The complex $\left[\mathrm{Cu}(\mathrm{SBH})_{2}\right]$ showed a few similar spectral bands but the amide bands, particularly the amide I and $v(\mathrm{~N}-\mathrm{H})$ stretching bands had disappeared in the complex indicating the absence of the $>\mathrm{C}=\mathrm{O}$ group and loss of the $\mathrm{NH}$ proton via enolisation indicating that the ligands are coordinating in the enolic form ${ }^{6}$.

Table 2: Important IR Spectral Data $\left(\mathrm{cm}^{-1}\right)$ of Copper Complex of SBH.

\begin{tabular}{lclllll}
\hline $\begin{array}{l}\text { Ligand } \\
\text { Complex }\end{array}$ & $\begin{array}{l}v(\mathrm{OH})+ \\
v(\mathrm{NH})\end{array}$ & $v(\mathrm{C}=\mathrm{N})$ & $\begin{array}{c}\text { Amide } \\
\mathrm{I}\end{array}$ & $\begin{array}{c}\text { Amide } \\
\text { II }\end{array}$ & $\begin{array}{l}\text { Amide } \\
\text { III }\end{array}$ & $v(\mathrm{~N}-\mathrm{N})$ \\
\hline $\mathrm{SBH}$ & 3280 & $1630_{\mathrm{m}}$ & $1675_{\mathrm{s}}$ & $1535_{\mathrm{s}}$ & $1275_{\mathrm{s}}$ & $995_{\mathrm{w}}$ \\
$\mathrm{Cu}(\mathrm{SBH})_{2}$ & $\begin{array}{c}v(\mathrm{OH}) \\
\end{array}$ & $\frac{2 \mathrm{C}=\mathrm{N}-\mathrm{N}=\mathrm{C}<}{1600_{\mathrm{s}}}$ & $\frac{v \mathrm{NCO}^{-}}{1500_{\mathrm{w}}}$ & $1030_{\mathrm{w}}$ \\
\hline
\end{tabular}

$\mathrm{s}=$ sharp, ${ }_{\mathrm{b}}=$ Broad, ${ }_{\mathrm{w}}=$ weak, $\mathrm{m}=$ medium 
After enolization, the IR spectra of the complex $\left[\mathrm{Cu}(\mathrm{SBH})_{2}\right]$ showed some new bands. A sharp band at $1600 \mathrm{~cm}^{-1}$ diagnostic of $>\mathrm{C}=\mathrm{N}-\mathrm{N}=\mathrm{C}<$ group $^{7}$ indicating transformation of the carbonyl group to its enolic form through keto-enol tautomerism and subsequent coordination of the enolic oxygen to metal after deprotonation. Again the appearance of a new band at $1500 \mathrm{~cm}^{-1}$ was characteristic of $v\left(\mathrm{NCO}^{-}\right)$ vibration $^{8}$, which further supported the enolic oxygen coordination. A weak band, $v(\mathrm{~N}-\mathrm{N})$ appearing at $995 \mathrm{~cm}^{-1}$ in the ligand shifted to higher frequency $1030 \mathrm{~cm}^{-1}$ in the complex which shows coordination through one of the nitrogen atom of the hydrazide moeity ${ }^{1}$. A broad band around $3400 \mathrm{~cm}^{-1}$ in complex showed non involvement of -OH group of salicylaldehyde in coordination.

\section{Electronic Spectra}

The electronic absorption spectra are often very helpful in the evaluation of results furnished by other methods of structural investigation. The electronic spectra measurements were used for assigning the stereochemistry of metal ions in the complexes based on the positions and number of d-d transition peaks.

The electronic spectrum of $\mathrm{Cu}$ (II) complex showed only one single broad band at $419 \mathrm{~nm}$, which is attributed to ${ }^{2} \mathrm{~T}_{2} \rightarrow{ }^{2} \mathrm{E}$ transition indicating tetrahedral coordination environment. This transition results from the hole transfer from $t_{2}$ to e orbital.

But regular tetrahedral derivatives of $\mathrm{Cu}$ (II) are very uncommon; there is usually a flattening of tetrahedron, presumably as a consequence of the Jahn-Teller effect lifting the degeneracy of the ${ }^{2} \mathrm{~T}_{2}$ ground state. However if copper is subjected into a tetrahedral lattice site, the Jahn-Teller effect has to work against the forces maintaining the lattice and distortion is expect to be minimized ${ }^{9}$.

\section{Conclusions}

The ligand, salicylaldehyde benzoyl hydrazone was found to coordinate with $\mathrm{Cu}$ (II) in enolic form. The composition corresponds to a 1:2 metal: ligand ratio. It doesn't contain any water molecules (lattice as well as coordinate) and anions. The IR spectra showed coordination through enolic oxygen and azomethine nitrogen. Electronic spectral studies showed tetrahedral stereochemistry. Based on these physico-chemical studies, the structure as shown in Fig. 5 have been tentatively proposed for copper complex with ligand Salicylaldehyde benzoyl hydrazone.

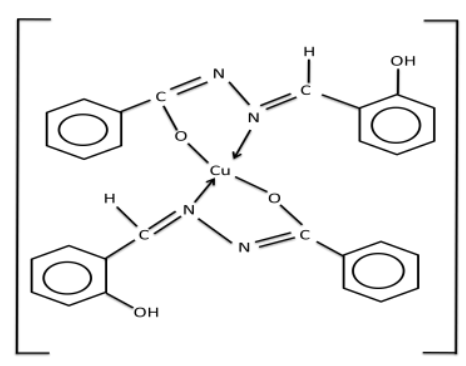

Figure 5: Proposed Structure of $\left[\mathrm{Cu}(\mathrm{SBH})_{2}\right]$

\section{Acknowledgements}

Authors would like to thank Department of Chemistry, Trichandra Multiple Campus for providing the laboratory facility, Dr Kanti Shrestha (NAST) for recording UV-VIS spectra and Dr. Nabeen Kumar Shrestha for his help in recording the IR Spectra. 


\section{References}

1. K. K. Narang, T. R. Rao, S. Shrestha and S. Shrestha., Synth. React. Inorg. Met. Org. Chem., 2000,30 (5), 931-954.

2. K. K. Narang, V. P. Singh, S. K. Singh and G. D. Mishra, Synth. React. Inorg. Met.Org. Chem., 1996, 23(7),191-209.

3. Z. Zabicky, The Chemistry of Amides, Interscience Publishers, London, 1970.

4. A. I. Vogel, A Text Book of Quantitative Inorganic Analysis, ELBS, London, 1978.

5. C. N. R. Rao, Chemical Application of Infrared Spectroscopy, Academic Press, New York, 1963.

6. M. Mohan, A. Kumar, M. Kumar and N. K. Jha, Inorg. Chim. Acta, 1987, 136, 65.

7. L. El. Sayeed and M.F. Iskander, J. Inorg. Nucl. Chem., 1971, 33, 435.

8. M. Mashima, Bull. Chem. Soc. Japan,1967,35,2347, 2020.

9. A. B. P. Lever, Inorganic Electronic Spectroscopy, $2^{\text {nd }}$ ed; Elsevier: New York, 1984. 